\title{
Using Interactive Technologies in Teaching an Online Information Systems Course
}

\author{
Thomas M Connolly and Mark Stansfield \\ University of Paisley, Paisley, Scotland
}

\section{thomas.connolly@paisley.ac.uk mark.stansfield@paisley.ac.uk}

\begin{abstract}
eLearning has profoundly changed many aspects of society and, inevitably, it is having a significant impact on Higher Education, where it has now evolved from a marginal form of education to a commonly accepted alternative to traditional face-to-face education. The term can cover different delivery models ranging from courses that are delivered fully online (no face-to-face meetings) to courses that provide some face-to-face interaction and some online provision (sometimes called blended learning). Within this continuum interactive technologies can play a significant role in engaging the learner and providing a rich learning experience. This paper examines how different interactive technologies can be used to enrich the learning experiences of students with different learning styles. The theory is related to the teaching of Information Systems in a postgraduate MSc Management of eBusiness course that uses a range of interactive technologies.
\end{abstract}

Keywords: eLearning, interactive technologies, games-based eLearning, motivation, information systems.

\section{Introduction}

The field of Information Systems (IS) is a diverse and evolving area of study that embraces many disciplines. An important issue within the field of IS is how to teach the range of skills required by IS professionals, which include those of a technical, managerial, social, and organizational nature within a rich and engaging learning environment. The MSc Management of eBusiness is an innovative course offered by the School of Computing at the University of Paisley aimed at providing many of the IS-related skills that modern senior managers require to understand and effectively manage eBusiness solutions.

The course offers a range of IS, business, management, IT, and eBusiness related modules that enable business managers and IS professionals to understand fully the strategies and technologies that can harness the potential of the Internet and eBusiness. When developing the course, market research suggested that a fully online delivery model would provide senior managers with the freedom and flexibility to continue their full-time careers in industry as well as study at a time

Material published as part of this publication, either on-line or in print, is copyrighted by the Informing Science Institute. Permission to make digital or paper copy of part or all of these works for personal or classroom use is granted without fee provided that the copies are not made or distributed for profit or commercial advantage AND that copies 1) bear this notice in full and 2) give the full citation on the first page. It is permissible to abstract these works so long as credit is given. To copy in all other cases or to republish or to post on a server or to redistribute to lists requires specific permission and payment of a fee. Contact Publisher@InformingScience.org to request redistribution permission. and in a manner of their own choosing. This market research was carried out in the early 1990s, at a time when online learning was still a relatively new approach to teaching and learning (no fully online course had been developed at the University of Paisley). Thus, a significant amount of persuasion was necessary to get the course approved internally and validated externally. Now, however, online learning has evolved 
from a marginal form of education to a commonly accepted and increasingly popular alternative to traditional face-to-face education. In fact, as a result of the globalization of higher education, the push for mass higher education from both government and society, and to meet the growing needs of higher education in responding to demands for flexibility, widening participation, continuing education, and lifelong learning, institutions across the world are under pressure to adopt online models of delivery (Connolly, Stansfield, MacArthur, \& McLellan, 2005).

Some faculty members are strong proponents of online learning and believe online courses can provide educational opportunities to learners who would otherwise have to do without. They also believe that the quality of these courses can be comparable to traditional place-bound courses. However, there are also many faculty members who are suspicious of such courses and have significant reservations about the loss of face-to-face contact between instructor and learner. While not entirely rejecting this medium, many of these faculty members use a blended approach to learning (a 'middle ground').

We believe online learning can make a major contribution to the educational requirements in teaching IS-related concepts. To keep pace with changes in technology and to meet the increasing demands of the knowledge-based economy requires a highly-skilled and educated workforce capable of working collaboratively to address problems of a diverse economic, social, technical, and environmental nature. The key to success is in a large part continuing education, which means that online learning with its open access and opportunities for active collaboration in an egalitarian environment will have an important role to play in meeting future challenges (Stansfield, McLellan \& Connolly, 2004). In this paper we discuss how we have used a range of interactive technologies motivated by principles found in the constructivist epistemology to help provide the learner with the knowledge and higher-order skills necessary to work as an IS practitioner.

\section{Educational Issues}

At the start of the MSc Management of eBusiness course many students are likely to view knowledge as an authoritative given, that is right or wrong, that can be gained through rote and practice (surface) learning techniques, and that exists independently of context. By the time they graduate, students are expected to (Research Forum, 2005):

- have understood the relative and provisional nature of knowledge related to eBusiness and organizations;

- be able to generate new knowledge through critical enquiry and demonstrate it in an appropriate form;

- be able to form their own judgments from evidence and challenge the judgments of others;

- be able to synthesize and apply knowledge in various contexts, and

- approach performance and professional practice from a reflective, critical and evidenced base, rather than simply a competence one.

In themselves, these expectations are not unusual and are typical for many postgraduate IS courses. Our course has a vocational orientation and we expect our graduates to become professional IS practitioners typically in a multi-disciplinary environment. Previous approaches to educating IS students model scientific and engineering methodologies, with their focus on process and repeatability. In general, this approach is based on a normative professional education curriculum, in which students first study basic science, then the relevant applied science, so that learning may be viewed as a progression to expertise through task analysis, strategy selection, tryout, and repetition. Students tend to cope well using this approach with many of the theoretical and practical components of the curriculum, for example, from more softer/people-oriented IS- 
related techniques such as systems maps and rich pictures to the more structured data-oriented ISrelated techniques such as dataflow diagrams and entity relationship diagrams. However, some of the abstract, less rule-based and complex areas such as knowledge elicitation and strategy formulation can be problematical for some students since they cannot always be readily applied within a realistic real-world environment that can be forgiving of mistakes and allow for feedback, reflection and opportunities to develop different problem-solving strategies to a range of problem scenarios. Waks (2001, pg. 39) argues that "the crisis of professions arises because real-life problems do not present themselves neatly as cases to which scientific generalizations apply".

Students often have considerable difficulty analyzing problems where there is no single, simple, well-known, or correct solution. They have difficulty handling ambiguity and vagueness and they can also display an inability to translate tutorial examples to other domains with analogous scenarios, betraying a lack of transferable analytical and problem-solving skills. Kriz (2003) highlights the point that the majority of students are not competent enough to put their knowledge into practice and they are unable to cope successfully with the everyday tasks associated with the practice of their chosen field. These problems can lead to confusion, a lack of self-confidence, and a lack of motivation to continue. In teaching information systems we are, as Postman and Weingartner (1971) state, "trying to help students to become more efficient problem solvers", avoiding "the right answer that only serves to terminate further thought" and reach a position where the student "must learn to depend on himself as a thinker".

IS can be considered as a wicked problem, characterized by incomplete, contradictory and changing requirements, and solutions that are often difficult to recognize as such because of complex interdependencies (DeGrace \& Hulet Stahl, 1998). According to Armarego (2002), there is an educational dilemma in teaching such problems because:

- complexity is added rather than reduced with increased understanding of the problem;

- metacognitive strategies are fundamental to the process;

- a rich background of knowledge and intuition are needed for effective problem-solving;

- a breadth of experience is necessary so that similarities and differences with past strategies are used to deal with new situations.

While online learning has many advantages (“anytime, anywhere, anypace”) there are also disadvantages such as increased setup costs, more responsibility is placed on the learner who has to be self-disciplined and motivated, increased workload on students and staff, non-involvement in the virtual community may lead to feelings of loneliness, low self-esteem, isolation, and low motivation to learn, which in turn can lead to low achievement and dropout, and dropout rates tend to be higher than in traditional face-to-face programs, often 10 to 20 percentage points higher (Connolly \& Stansfield, 2006). To address these issues we require a different approach to traditional (face-to-face) teaching methods.

\section{eLearning}

\section{What is eLearning?}

The term eLearning has been used to describe an educational setting in which teaching and learning take place within an Internet-based environment (Berge \& Collins, 1995) and as "the use of digital technologies and media to deliver, support and enhance teaching, learning, assessment and evaluation" (LTSN, 2003, pg. 6). In this paper we distinguish between 'online learning' and 'eLearning'. We use the term online learning to represent any class that offers its entire curriculum via the Internet thereby allowing learners to participate regardless of geographic location (place-independent), theoretically 24 hours a day (time-independent). This is in contrast to the 
traditional classroom instruction, which is time and place bound, face-to-face, typically conducted in an educational setting and consisting primarily of a lecture/note-taking model, and blended learning, which is a combination of online learning and traditional classroom instruction. We use eLearning as a generic term to encompass both (fully) online learning and blended learning.

The instructional media elements employed within the context of this definition of eLearning could consist of text, video, audio, graphics, animation, or any combination thereof. A central component of most eLearning courses is some form of two-way interaction between learners and their instructor and between the learners themselves. Synchronous communication tools such as real-time chat and asynchronous tools such as email and discussion boards are common.

eLearning is an evolved form of distance education. Nipper (1989) identifies three generations of distance education. The first generation, sometimes referred to as the 'correspondence model', was provided mostly through paper-based instruction, characterized by the mass production of educational materials. The difficulty with correspondence education has been the infrequent and inefficient form of communication between the instructor and the learners. Further, it was difficult to arrange for peer interaction in correspondence based distance education. The second generation, sometimes referred to as the 'multimedia model', was provided through integrated multimedia such as delivering courses via television or introducing material like audio and video tapes, computer-based learning (CBL) in addition to printed material. The third generation was provided through two-way communications media such as audio/video-conferencing and broadcast technology.

Taylor (2001) defines two further models of distance education that introduce the medium of the Internet. The fourth generation features online delivery of interactive multimedia, access to Internet resources, and computer-mediated communication (CMC). This latter facility enabled instructors to introduce digitally-mediated asynchronous interactions with and among learners, allowing instructor and learners to be separated in both time and distance. The fifth generation includes the fourth generation features but adds systems that streamline course production and learner services.

We would argue that Taylor's fourth and fifth generation models can now be divided into three generations, representing more sophisticated usage of the Internet and interactive technologies. The fourth generation of distance education (the first generation of eLearning) we define as mainly passive use of the Internet, consisting primarily of conversion of course material to an online format, low-fidelity streamed audio/video, and basic mentoring using email. However, the educational philosophy still belongs to the pre-Internet era. The fifth generation of distance education (the second generation of eLearning) uses more advanced technologies consisting of highbandwidth access, rich streaming media, online assessment (eAssessment), and Virtual Learning Environments (VLEs) that provide access to course material, communication facilities, and learner services. The sixth generation of distance education (the third generation of eLearning) is a more collaborative learning environment based much more on the constructivist epistemology, promoting reflective practice through tools like ePortfolios, blogs, wikis, online communities, and using interactive technologies such as online visualizations, games, and simulations. We are also now starting to see the development of mLearning (mobile learning) through devices like PDAs (Personal Digital Assistants), mobile phones, and smartphones. Initial results on the use of mLearning have been encouraging and research suggests, for example, that mLearning enhances autonomous and collaborative learning and that it can be applied to a wide age range of learners. mLearning is still at an early stage but as these devices become more functional and commonplace we would expect to see significant developments in this area. mLearning has the potential to provide truly "anywhere" learning. 


\section{Applying eLearning to the MSc Management of eBusiness}

The development of the MSc Management of eBusiness in an online format began about a decade ago after detailed consultation with a number of major organizations who were seeking a more flexible method of learning for their senior managers than provided by the University of Paisley's more traditional face-to-face programmes. We have discussed the development and evaluation of this course elsewhere (for example, Stansfield et al, 2004; Connolly et al, 2005). In this section, we discuss the initial structure of the online materials for the first few cohorts of this course.

The online materials are provided in two levels to accommodate different student learning styles. The first level consists of static text versions of the module materials available in PDF format with relevant diagrams and tables embedded in the text. The second level includes an interactive web-based version, which provides interactive graphic-rich summaries of concepts described in level 1 . As well as interactive visualizations, the materials include hyperlinks that students can use to explore the material in either a highly structured sequential manner or in a less structured manner to encourage independent learning. In addition, level 2 contains online self assessments for students to gauge their own progress. Students can either enter at level 1 or 2 and can switch between levels at appropriate points.

In addition, there are also weekly asynchronous conference tutorials that require students to carry out specific tasks relating to the topics being explored that week. This allows students to interact with the module tutor as well as with each other and to receive relatively immediate feedback from the tutor about their progress. Students also have access to a private discussion forum that is not accessible by faculty, to discuss matters relating to the module or course and to support a sense of 'community'.

From the student questionnaires taken at the end of each module, it was evident that the students were extremely satisfied with the online learning format and, given the opportunity, would take another module in this form (93\%). The students were also very satisfied with the structure of the online modules (98\%) and found the modules both easy to read and understand (91\%) and interesting and enjoyable (91\%). No students reported feeling isolated, primarily as a result of the interactions from instructors and peers. Perhaps surprisingly, only $63 \%$ of students used the interactive materials, the remainder using only the text-based versions of the materials. Upon further investigation, some students reported that the standard look-and-feel was useful for the text-based materials but wanted more variety with the interactive materials.

From faculty feedback, one aim of the course that was felt difficult to achieve was allowing students to contextualise their learning by being able to apply it within a realistic real-world setting in which they could more easily 'learn by doing'. The case studies used within the eLearning environment were text-based in nature and could not provide a situated understanding of the concepts being covered nor could they provide effective ways of enabling interaction among students in developing team-working skills.

As a result of these comments, it was decided to explore whether computer games-based technologies might have enhanced the eLearning environment by providing a more realistic realworld setting for the application of theoretical concepts, enabling tasks to be explored collaboratively, while providing more variety with the interactive materials.

\section{Games-based eLearning}

\section{What is Games-based eLearning?}

Before defining games-based eLearning, we first discuss two underlying concepts: simulations and games. Greenblat (1981) defines a simulation as an operating model of some system while 
Crookall and Saunders (1989) view a simulation as a representation of some real-world system that can also take on some aspects of reality for participants and users. Key features of simulations are that they represent real-world systems, contain rules and strategies that allow flexible and variable simulation activity to evolve, and the cost of error for participants is low, protecting them from the more severe consequences of mistakes (Garris, Ahlers, \& Driskell, 2002). Simulations are often created to engage the learner in situations or events that would be too costly, difficult, or hazardous in real life, or that may be considered unethical.

Caillois (1961) defines a game as an activity that is voluntary and enjoyable, separate from the real world, uncertain, unproductive (in that the activity does not produce any goods of external value) and governed by rules. Crookall, Oxford, and Saunders (1987) believe that a game is not intended to represent any real-world system (unlike a simulation), rather it is 'separate from the real world'. Like simulations, games also contain rules and strategies but the costs of losing are generally only consequential within the game world. Prensky (2001) defines the key characteristics of games as: rules, goals and objectives, outcomes and feedback, conflict (and/or competition, challenge, opposition), interaction, and representation of story.

The terms 'computer game' and 'video game' were used in the past to refer to PC-based games and console-based games, respectively, but are generally now used interchangeably. Cruickshank (1980) uses the term simulation game as one "in which participants are provided with a simulated environment in which to play". For the purposes of this paper, we will use the term 'computer game' generically to include both computer games and computer simulations for PCs, games consoles, and mobile devices.

We define games-based eLearning as "the use of a computer games-based approach to deliver, support, and enhance teaching, learning, assessment, and evaluation" and differentiate it from the more common term games-based learning, which tends to cover both computer and noncomputer games, such as card and board games. This is a research area that may be conceptualized as the intersection of learning theory, computer games theory and design, user interfaces, and subject matter expertise. In this conceptualization, learning theory serves as the foundation to ensure that technology does not become the dominant factor.

\section{Why Games-based eLearning?}

There is some debate about whether the arrival of digital technology has been a "big discontinuity ... a 'singularity' - an event which changes things so fundamentally that there is absolutely no going back" and has created fundamental differences between the younger generation (digital natives) and the older generation (digital immigrants). Connolly et al (2005) have observed that some learners exhibit a cognitive preference for certain media. For example, the younger generation likes portability and are frustrated by technology that ties them to a specific location and studies show that they do not read as much as previous generations but prefer video, audio, and interactive media. Some have argued that the younger generation have a shorter attention span and require learning in 'small size chunks', however, Brown (2004) found that their attention span parallels that of top managers. Others argue that the younger generation learn more collaboratively than previous generations and demonstrate a bias towards learning in situ. On the other hand, Owen (2004) argues that the differences are not that significant and cites examples of how 'digital immigrants' use as much, if not more, technology, than the younger generation.

Regardless of whether there is a difference between these two generations, there is a growing body of research within the theories of learning and instruction that believe computer games have highly desirable qualities worthy of further investigation. Connolly, Stansfield, McLellan, Ramsay, and Sutherland (2004) suggest that computer games build on theories of motivation, constructivism, situated learning, cognitive apprenticeship, problem-based learning, and learning by 
doing. By creating virtual worlds, computer games integrate “...not just knowing and doing. Games bring together ways of knowing, ways of doing, ways of being, and ways of caring: the situated understandings, effective social practices, powerful identities, and shared values that make someone an expert” (Shaffer, Squire, Halverson, \& Gee, 2004).

In addition to the cognitive dimension of knowledge and skills and the emotional dimension of feelings and motivation, there is also a growing recognition that learning also encompasses the social dimension of communication and cooperation - all three of which are embedded in a societally situated context (Illeris, 2002). In this section we examine some of the social aspects of computer games that may lead to enhanced learning. Communities of practice (Lave \& Wenger, 1991) in a professional context and communities of learners in an education context (Brown \& Campione, 1994) have focused on how individual development occurs within the context of the norms and activities of a community. Communities of practice are “... groups of people who share a concern, a set of problems, or a passion about a topic, and who deepen their knowledge and expertise in this area by interacting on an ongoing basis” (Wenger, McDermott, \& Snyder, 2002, pg. 4). Learning occurs through participation in the practices of a community, as individuals develop ways of thinking and reframe their identities and interests in relation to the community. A desirable feature of online learning communities is that there exists varying demands and expertise at different levels of competency where participants can scaffold one another through the sharing of information and abilities. Strong community is important as it has been shown to lead to deep learning (Chapman, Ramondt, \& Smiley, 2005).

The above concepts of community and social activity do not immediately seem applicable to computer games. However, while the stereotypical perception of a gamer is someone who is young (probably male), somewhat 'nerdy', unable to communicate, introverted, and lacking in basic social skills, this is now far from the truth. The last decade has seen the rise of multiplayer games and online (virtual) gaming communities. Not only do gamers play these games together but in some cases they help extend and improve the games through tools that the games developers provide or even tools that the 'community' develops. There are now countless gaming community websites that host discussion forums and blogs and where game reviews, communitywritten manuals, walkthroughs, tips, hints, faqs, and 'cheats' are available. For example, massive multiplayer online games (MMOG) allow hundreds of thousands of players to simultaneously interact in graphically rendered immersive worlds. MMOGs generally create a persistent universe where the game continues playing regardless of whether or not anyone else is playing. The most popular of these games to date are World of Warcraft and Lineage, both of which have reportedly more than 4 million players world-wide. These games are not games in the traditional rules-based sense, but rather "persistent social and material worlds, loosely structured by open-ended (fantasy) narratives, where players are largely free to do as they please" (Steinkuehler, 2004). Generally the game play mechanics are such that true mastery of the game can often only be achieved by working collaboratively with other players, which contributes to a substantial sense of community.

Such games represents an entirely new kind of social learning experience and "understanding the social practices and constructivist ecologies being created around open source and massively multiplayer games will provide a glimpse into new kinds of innovation ecologies and some of the ways that meaning is created for these kids - ages 10 to 40. Perhaps our generation focused on information, but these kids focus on meaning - how does information take on meaning?” (Brown, 2004). A more comprehensive discussion of games-based eLearning and the advantages and disadvantages of games-based eLearning can be found in Connolly and Stansfield (2006). 


\section{Examples of Games-based eLearning in Higher Education}

In recent years there have been an increasing number of games-based eLearning applications that have been developed across a wide range of subject areas and disciplines. In this section, we briefly examine two examples that have influenced our games-based eLearning development.

\section{Management and administration}

The aim of the computer-based simulation game Virtual U (http://virtual-u.org), modelled after the popular SimCity series, is to train university administrators and graduate students to deal with the growing complexities and challenges of running a modern university, including meeting the needs of an increasingly diverse student population as well as developing the advanced technology infrastructure that is now necessary to meet the needs of students, faculty, and administrators. The game focuses on running a university or college and takes into consideration a variety of stakeholders including faculty, administrators, students, governing boards, and parents. While Virtual $\mathrm{U}$ is a simulation, it is grounded in authentic data from 1,200 universities and colleges in the United States.

The game challenges players to act as a President of a university/college and attempt to manage the institution's affairs, based on a number of scenarios. Players can set, monitor, and modify a variety of institutional parameters and policies that result in the success or failure of the institution. For example, players can set tuition costs and allocate resources for research, financial aid, faculty salaries, facilities, and fund raising. Modifying the value of one parameter can have a consequential effect on other parameters. At the same time, random events occur requiring the players to establish an immediate plan of action. Progress can be checked as time goes by and a letter of review is received from the Board each 'year', a rite of passage established by the player. Figure 1 provides two screenshots from the game, one showing the campus (each building represents a particular faculty/department and can be selected to obtain relevant data) and the other showing a typical set of departmental figures.
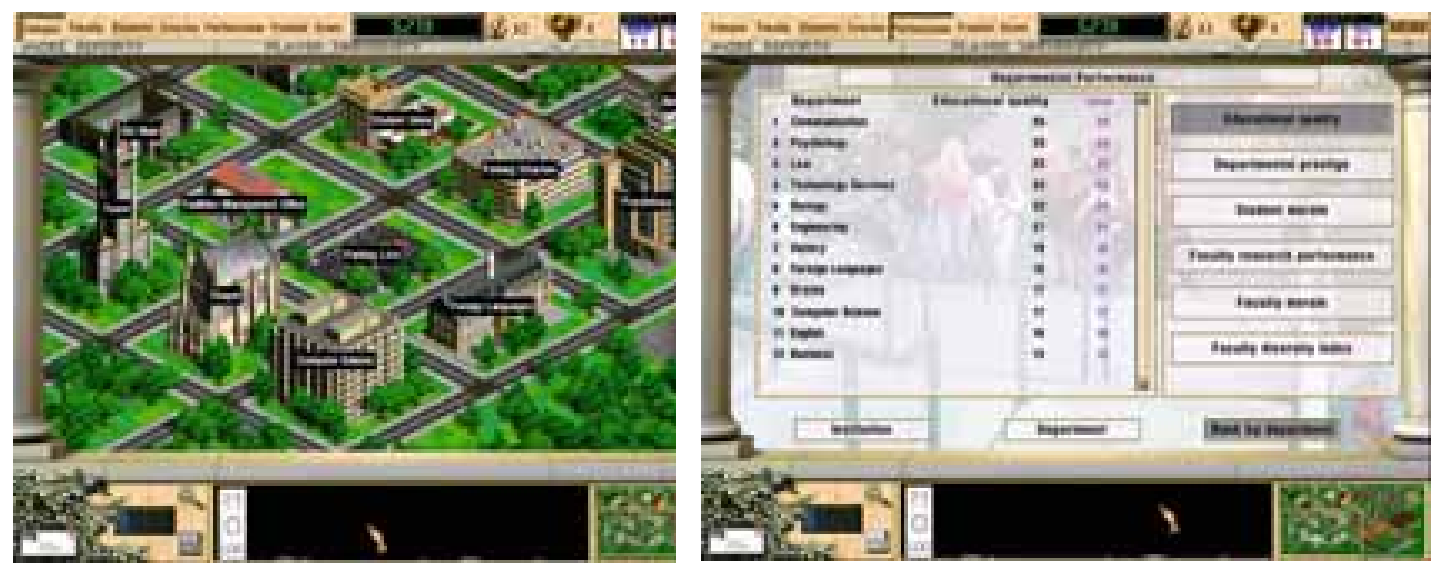

Figure 1: Screenshots from Virtual U

\section{Business}

KM Quest (http://www.kmquest.net) is a web-based simulation game aimed at developing core knowledge management skills with situated problems using collaborative learning. It is a teambased game in which up to 3 players are responsible for a fictitious company called Coltec $-\mathrm{a}$ product leadership organization. The general goal of the simulation game is to optimize the level of a set of general organizational effectiveness variables: market share, profit, and customer satis- 
faction index. Players act as knowledge managers for 3 consecutive years in the life span of the company, with each year divided into quarters. During this time, they can inspect the status of business process indicators and knowledge process indicators, ask for additional information, and choose interventions in an attempt to change the behavior of the business simulation. Most indicators are characterized by a decay factor so that the value of an indicator decreases over time when no interventions are implemented. Players are given a budget at the start of the game that they can use to implement interventions and buy information. At the start of each quarter players are confronted with an event that could affect the knowledge household of Coltec and they have to decide if and how they want to react to these events. When they think they have enough information to solve the problem, they agree the proposed intervention and the game proceeds to the end of the quarter and calculates new values for each of the business indicators.

Before the game starts, players are given an introduction to the basic concepts of knowledge management and training on the game. The training consists of a limited form of the game with restricted choices and fixed events during which guidance, coaching, and immediate feedback is given (based on the cognitive apprenticeship model). Leemkuil, de Jong, de Hoog, and Christoph (2003) provide a formative evaluation of this simulation game.

\section{Applying Games-based eLearning to the MSc Management of eBusiness}

As the next stage in the development of the online version of the MSc Management of eBusiness, we decided to investigate the use of a games-based eLearning prototype that would provide a collaborative real-world setting within which to explore concepts relating to elements of the course. Rather than replacing the eLearning environment that had already been 'tried and tested' a games-based simulation was developed to enhance the existing framework with its many advantages by adding an additional entry level, as shown in Figure 2. Level 3 provides the student with access to a full 3D game, which in turn provides access to the other entry levels at appropriate points (using a cognitive apprenticeship approach).

The game is based around a marina called Fair Winds Marina and has been developed as a collaborative project between two Scottish higher education institutions. The game allows teams of students, acting in the role of Information Systems consultants, to conduct information systems requirements analysis of the Marina's needs and produce an IT specification aimed at improving problems that they identify within the business. The game is a first person walkthrough in which the students take on identities of people in the game and can walk around the Marina into its various offices and buildings and meet with different employees such as the owner, the sales manager, and the shop manager to identify possible problems, determine their information systems requirements, as well as the most appropriate ways of addressing the problem situation. The game is discussed further in Connolly et al (2004).

The development of a rudimentary prototype of the Fair Winds Marina game has taken roughly thirty man months of effort. Whilst the development of the prototype has been successful in that it provides an indication of the types of learning experiences that can be offered, it is nowhere near the quality of commercial games that take many years and Emillions to fully develop. Clearly, academic institutions cannot afford the immense time and resources to develop such games to a commercial standard. We are concerned that anything significantly below the quality of a commercial game may have a negative impact on learning as students may not become fully engaged nor motivated to play the game, and eventually lose patience with the game's limitations. A further problem that has been identified in the development of the prototype concerns the issue of scalability and whether it can easily be adapted to present other types of problem scenarios and tasks. As we want our students ideally to gain knowledge and experience through exposure to different scenarios this poses a significant problem. 
Given that we face increased costs to fully realize our plans, and given that this genre of game may only suit the learning styles of some of the students, we are now developing a 2D/2.5D simulation game that reduces the complexity of the underlying software development and focuses instead on providing students with a wider range of eBusiness scenarios appropriate to the course. The new game is based around the type of environment created in Virtual U and KM Quest, discussed in the previous section.

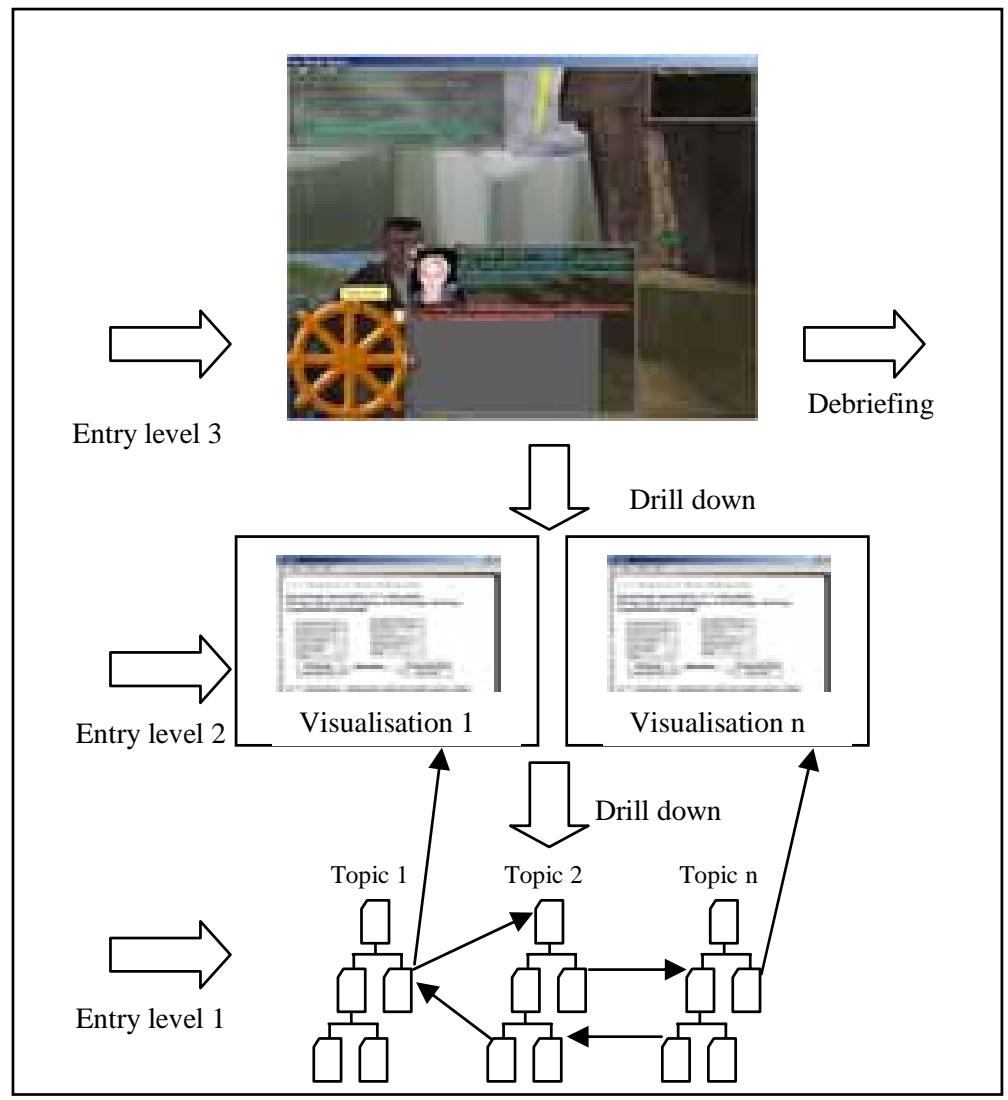

Figure 2: Three-level games-based eLearning architecture being developed for the MSc Management of eBusiness

\section{Summary and Future Directions}

There is a significant revolution under way in approaches to pedagogy and student learning across education as a whole towards more individualized and learner focused approaches enabled by the innovative use of eLearning technologies. In particular, there is growing realization of the limitations of traditional VLEs with their emphasis often on the institutional delivery of curriculum content and more limited development of the dynamic learning supported online. Within this context, we believe that interactive technologies have the potential to enhance the development of IS knowledge and skills. If eLearning has developed a reputation for being 'boring and mindless', games have developed the reputation for being engaging and challenging (Aldrich, 2003). Interactive technologies can provide this engagement but our students were also looking for a variety of computer-based interactions, rather than a standard 'look-and-feel' to all interactivity. It is accepted that games-based eLearning will not be for all learners and it is accepted that there may be issues surrounding development costs. However, there are case studies of successful use of games-based eLearning and we believe that further work should be carried out on various aspects 
of games-based eLearning to more fully understand their potential and limitations. For example, learning through community has been demonstrated to be successful in games communities. This is an area that needs further research to identify more fully how learning takes places in these informal environments and to identify how, or even whether it is possible, to transfer this process into formal learning environments.

Given the perceived link between violence and social maladjustment and the high development costs of games-based eLearning, and given the fact that many faculty members have still not fully embraced eLearning, in the short to medium term games-based eLearning will only occupy a small section of the higher education eLearning market. This has given rise to the opinion that within a higher education context where resources are generally scarcer than found in the corporate world, a less sophisticated virtual games environment that is easier to adapt as well as being scaleable while at the same time being less resource intensive to develop might be a more realistic aim for the academic community to consider. A secondary route may be the development of games-based eLearning in partnership with commercial games companies.

\section{References}

Aldrich, C. (2003). Simulations and the future of learning: An innovative (and perhaps revolutionary) approach to e-Learning. New York: Pfeiffer.

Armarego, J. (2002). Advanced software design: A case in problem-based learning. Proceedings of the 15th Conference on Software Engineering Education and Training, 25-27 February 2002, Covington, Kentucky, USA, pp. 44-54.

Berge, Z.L. \& Collins, M. (Eds.) (1995). Computer-mediated communication and the online classroom. Cresskill, NJ: Hampton Press.

Brown, J.S. (2004). Growing up digital: How the web changes work, education and the ways people learn change. Retrieved 10 September 2004 from http://www.johnseelybrown.com/speeches.html

Brown, A.L. \& Campione, J.C. (1994). Guided discovery in a community of learners. In K. McGilly (Ed.), Classroom lessons: Integrating cognitive theory and classroom practice (pp. 229 - 270). Cambridge, MA: Massachusetts Institute of Technology.

Caillois, R. (1961). Man, play, and games. New York: Free Press.

Chapman, C., Ramondt, L., \& Smiley, G. (2005). Strong community, deep learning: exploring the link. Innovations in Education and Teaching International, 42(3), 217 - 230.

Connolly, T.M. \& Stansfield, M.H. (2006). From eLearning to Games-based eLearning: Using Interactive Technologies in Teaching Information Systems. Manuscript submitted for publication.

Connolly, T.M., Stansfield, M.H., MacArthur, E., \& McLellen, E. (2005). A quasi-experimental study of three online learning courses in computing. Journal of Computers and Education.

Connolly, T.M., Stansfield, M.H, McLellan, E., Ramsay J., \& Sutherland J. (2004). Applying computer games concepts to teaching database analysis and design. International Conference on Computer Games, AI, Design and Education, Reading, UK, November 2004.

Crookall, D., Oxford, R.L., \& Saunders, D. (1987). Towards a reconceptualization of simulation: From representation to reality. Simulation/Games for Learning, 17, 147-171.

Crookall, D. \& Saunders, D. (1989). Towards an integration of communication and simulation, In D. Crookall \& D. Saunders (Eds.), Communication and simulation: From two fields to one them. Clevedon, UK: Multilingual Matters.

Cruickshank, D.R. (1980). Classroom games and simulations. Theory into Practice, 19(1), 75-80.

DeGrace, P. \& Hulet Stahl, L. (1998). Wicked problems, righteous solutions: A catalog of modern engineering paradigms. Prentice Hall. 
Interactive Technologies in Teaching an Online Information Systems Course

Garris, R., Ahlers, R., \& Driskell, J.E. (2002). Games, motivation, and learning: A research and practice model. Simulation and Gaming, 33(4), 441-467.

Greenblat, C. (1981). Teaching with simulation games: A review of claims and evidence. In R. E. Duke \& C. Greenblat (Eds.), Principles of practice of gaming-simulation. London: Sage Publications.

Illeris, K. (2002). The three dimensions of learning: Contemporary learning theory in the tension field between the cognitive, the emotional and the social. Copenhagen: Roskilde University Press.

Kriz, W.C. (2003). Creating effective learning environments and learning organizations through gaming simulation design. Simulation \& Gaming, 34(4), 495-511.

Lave, J. \& Wenger, E. (1991). Situated learning: Legitimate peripheral participation. Cambridge, England: Cambridge University Press

Leemkuil, H., de Jong, T., de Hoog, R., \& Christoph, N. (2003). KM QUEST: A collaborative Internetbased simulation game. Simulation \& Gaming, 34(1), 89-111.

LTSN. (2003). A guide for learning technologists. Learning and teaching support network, LTSN Generic Centre, E-Learning Series 4.

Nipper, S. (1989). Third generation distance learning and computer conferencing. In R. Mason \& R. Kaye (Eds.), Mindweave: Communication, computers and distance education (pp. 53-73). Oxford: Pergamon.

Owen, M. (2004). The myth of the digital divide. Nesta FutureLab Viewpoint Article 26, Retrieved 23 October 2005 from http://www.nestafuturelab.org/viewpoint/art26.htm

Postman, N. \& Weingartner, C. (1971). Teaching as a subversive activity. London: Penguin.

Prensky, M. (2001). Digital game based learning. McGraw-Hill.

Research Forum. (2005). The relationship between research and teaching in institutions in higher education, Forum's advice to ministers on teaching and research. Higher Education Research Forum. Retrieved 20 October 2005 from http://www.dfes.gov.uk/hegateway/hereform/heresearchforum/index.cfm

Shaffer, D.W., Squire, K.T., Halverson, R., \& Gee, J.P. (2004). Video games and the future of learning. Phi Delta Kappan.

Stansfield, M., McLellan, E., \& Connolly, T.M. (2004). Enhancing student performance in online learning and traditional face-to-face class delivery. Journal of Information Technology Education, 3, 173-188. Available at http://jite.org/documents/Vol3/v3p173-188-037.pdf

Steinkuehler, C.A. (2004). Learning in massively multiplayer online games. Proceedings of the Sixth International Conference of the Learning Sciences, pp. 521-528

Taylor, J. (2001). Fifth generation distance education. Keynote Address presented at the $20^{\text {th }}$ ICDE World Conference, Düsseldorf, Germany, April 2001.

Waks, L.J. (2001). Donald Schon's philosophy of design and design education. International Journal of Technology and Design Education, 11, 37-51.

Wenger, E., McDermott, R., \& Snyder, W.S. (2002). Cultivating communities of practice. Boston: Harvard Business School Press.

\section{Biography}

Thomas Connolly is a Professor in the School of Computing at the University of Paisley. Thomas worked for over 15 years in industry as a Manager and Technical Director in international software houses before entering academia. His specialisms are eLearning, games-based eLearning and database systems.

Mark Stansfield is a Senior Lecturer in the School of Computing at the University of Paisley. He has a $\mathrm{PhD}$ in Information Systems and has published papers on eLearning, games-based eLearning and information systems in a number of international journals. 